voluntary consent. These workers have done the only experimental studies in the world on this important contemporary question. Shah's well known article on dangerousness and civil commitment, published in 1975 , certainly stands reprinting, as does Loren Roth's seminal paper proposing 'a commitment law for patients, doctors, and lawyers', in which he argues for safeguarded paternalism. Paternalism seems to be on the ascendancy in the United States as a reaction to an aggressive and legalistic approach to so-called individual rights which omits the right to be cared for. Macklin, in a 1981 paper, accepts that freedom is a fundamental value, but places alongside it other values such as justice, equity, equality, self-esteem, quality of life.

An important paper is Breggin's on 'The Return of Lobotomy and Psychosurgery'. This is partly because it hasn't previously been published in the medical literature (a number of journals declined it), partly because it was an important part of a debate in the United States in the early 1970s which reduced the number of leucotomy operations from the thousands to the hundreds, and partly because a strident author has shown the grace and honesty to change his mind. The paper is emotional and in places highly illogical, but it does call attention to some remarkable published assertions such as the claim that a patient who committed suicide after a leucotomy was a success because the suicide was a sign that she was recovering from the depression! The change of heart is not as profound as Vernon Mark (who is allowed a reply in the form of a badly argued paper from 1974) would have wished, but Breggin now believes that no form of treatment should be banned by legislation. 'Voluntary patients should be allowed to choose any therapy they wish for themselves, even if it is brain damaging'. Perhaps he should be invited to Britain to argue this point with our Members of Parliament who have now insisted that in this country patients should not be free to choose a leucotomy for themselves however competent they might be.

The book ends with sections on responsibility, commitment and the insanity defence, and on deinstitutionalisation. Neither of these sections reaches the standards of the earlier parts of the book. It is sad and salutory that treatment, especially chronic hospital treatment, somehow, even in a book of this kind, comes low down on the scales of both priority and quality.

Unlike many collections of reprinted papers this volume works and is fully recommended.

JOHN GUNN

Professor of Forensic Psychiatry Institute of Psychiatry

London

\section{Health for All: A Challenge to Research in Health Manpower Development}

Report of the XVIth CIOMS Round Table Conference, Ibadan, Nigeria, 1982, 229 pages, Geneva, SF20, World Health Organisation, 1983

The Council for International Organisations of Medical Sciences (CIOMS) is particularly concerned with biomedical sciences and the fact that it chose primary health care as the focus of its XVIth conference is very welcome. Too often 'high technology medicine' and 'primary care' are considered to be mutually exclusive alternatives whereas the principles of primary health care planning are as relevant for the most specialised hospital service as for the rural health worker.

In part the polarisation, in the $\mathrm{UK}$ at least, results from the use of the adjective 'community' to describe all services except hospital services, thus implying that the motives of those who work in hospital are not to serve the community but simply to do what interests them most. Hospital and laboratory services are, however, community services and primary health care principles - service to the whole population, effective and efficient use of resources by the appropriate use of technology, integrated rather than isolated planning, and the participation of users of the service in its planning and management - are of great relevance, as this conference recognises.

In part the debate about primary health care is a technical debate, focusing on issues such as the need to define different criteria for hospital care and domiciliary care, but there is also an ethical dimension to the primary health care approach for one of its keystones is the provision of health services to the whole population. If we consider the population of people with arthritis as an example, most health services in the world concentrate on the referred population, those who have brought themselves to, or been referred to, the appropriate source of help. In all 开 countries social and psychological $\overline{\bar{\gamma}}$ factors influence the probability that someone will be referred to a source of $\overrightarrow{\overline{\vec{F}}}$ specialist help: for example, the person whose brother is known to the general practitioner to be a consultant orthopaedic surgeon will probably be referred more quickly than the person who has no medical connections. In many countries financial factors os influence the access of patients to $\overrightarrow{0}$ services either directly, in countries in $\rightarrow$ which private practice is the main $\vec{\omega}$ source of health care, or indirectly because of the influences car and $\bar{\top}$ telephone ownership have on access to health services. The issue of equity was . addressed by conference speakers and $\overrightarrow{\vec{A}}$ was a major theme of the conference.

The conference was also important 음 because it recognised that health service $\rightarrow$ planning and management should be $z$ concerned not only with buildings and budgets but with a third 'B' - the $\frac{\rho}{\supset}$ behaviour of the professionals who work in the service. The term 'development' is used to mean not only growth in numbers but also change; change in skills, attitudes and values. How much should professional freedom be allowed to flourish unrestrained when it results in a concentration of health workers in the richest parts of a country? It is this type of issue that the conference discussed and there are some stimulating papers in the proceedings, notably that by Claudio Moura Castro from the Ministry of Planning in Brazil.

These reports will be of interest not only to the planners and managers of health centres but also to all those who wish to learn about the new approach to primary health care. They also demonstrate clearly that we have as much, if not more, to learn from developing countries than we have to teach them.

J A MUIR GRAY

Community Physician, Community Health Offices, Radcliffe Infirmary,

Oxford

Report on Euthanasia, Aiding Suicide and Cessation of Treatment

Report 201, Law Reform Commission of Canada, 35, Canada, 1983, available free of charge from the Law Reform글 